\title{
METABOLIC STUDIES IN PATIENTS WITH CANCER OF THE GASTRO- INTESTINAL TRACT. I. PLASMA VITAMIN A LEVELS IN PATIENTS WITH MALIGNANT NEOPLASTIC DISEASE, PARTICULARLY OF THE GASTRO-INTESTINAL TRACT ${ }^{1}$
}

\author{
By JULES C. ABELS,2 ALICE T. GORHAM, GEORGE T. PACK, \\ AND C. P. RHOADS \\ (From the Memorial Hospital, New York City)
}

(Received for publication July 30, 1941)

Cancer of the gastro-intestinal tract accounts for 54 per cent of the total mortality from neoplastic disease in males (1) -an incidence which warrants particularly intensive study of the disorder. The associated metabolic abnormalities are especially important, not only because through them some clue as to etiology may be found, but also to provide information by which the mortality from difficult operative or radiological procedures may be reduced.

The results of numerous clinical and experimental studies suggest that dietary factors are important in the maintenance of a normal gastrointestinal mucous membrane $(2,3)$. Hence, close attention has been given, in the Memorial Hospital, to the study of the nutritional status of patients with intestinal neoplasms. The results of the measurement of levels of vitamin $\mathrm{A}$ in the plasma, herein reported, are considered to be of special interest.

\section{MATERIAL}

Normal individuals were studied to establish the normal levels of vitamin A, carotene and thiamin in the blood, as well as of riboflavin in the urine. Adult laboratory technicians, house physicians, nurses, and normal young men, all apparently in good health and on adequate diets, were used as subjects.

The clinical material upon which this report is based includes six different groups of patients. The first is composed of 51 patients with cancer of the gastro-intestinal tract, selected from 62 consecutive admissions to the gastric and rectal services of the Memorial Hospital. Eleven of the 62 cases were discarded because they were febrile or had received medication which might provide misleading findings.

1 The author gratefully acknowledges the assistance given by the Jane Coffin Childs Fund, the Standard Brands, Inc., and the Dazian Foundation.

2 Finney-Howell Fellow.
The diagnosis of gastro-intestinal neoplasm was made by $\mathrm{x}$-ray, endoscopic procedure, laparotomy, biopsy, or a combination of these methods. Of the 51 patients studied, 28 had gastric, 18 rectal, and 5 esophageal cancer. Thirty-seven of the patients provided an opportunity for examination of the liver, either at autopsy or at operation. In 11, metastatic nodules were found, but in none were they sufficiently large to suggest the possibility of anatomical impairment of hepatic function.

Whereas all but 4 of the patients eventually exhibited the symptoms commonly associated with their diseaseprincipally weight loss, anorexia, changes in bowel habits, and abdominal pain or tenderness-only 6 had had nausea, vomiting, diarrhea or melena. All had various degrees of anemia. Fifteen had palpable abdominal or rectal masses.

Thirteen of the 51 patients had been on restricted diets, but the restriction did not apply to the intake of vitamincontaining materials. Indeed, most of the patients had taken a diet which was abnormally high in its content of carotenoids.

The second group of cases comprises 14 patients with benign gastro-intestinal lesions. Eight had peptic ulcers associated with continuous vomiting, anorexia, and weight loss. Of the remaining 6,2 had severe ulcerative colitis, 2 long-standing active sprue, and 2 mucous colitis; all 6 had had persistent diarrhea for from 1 to 10 years.

The third group consists of 19 patients whose gastrointestinal neoplasm had been removed surgically. In 12, the lesion originally was of the stomach, and in 7 , of the large bowel. At the time of laparotomy hepatic metastases had been present in only 1 of the 19, and that patient is now alive 5 years after the operation. When the vitamin A levels were determined in the plasma of the 19 post-operative patients, all were free of symptoms. Three of the 19 had been on grossly deficient diets for at least 4 months.

The fourth group of patients represents 20 routine admissions to the Head and Neck Service of the Hospital. These all had leukoplakia of the oral mucosa, without cancer or syphilis, and 5 had been on grossly deficient diets.

The fifth group consists of 13 patients admitted to the Gastric Service. In all, atrophy of the gastric mucosa was found by gastroscopic examination, all had symptoms 
referable to their disease, and 4 had been on grossly deficient diets.

In addition to the patients discussed, the vitamin $A$ levels were ascertained in the plasma of several smaller groups of individuals with cancer located elsewhere than in the gastro-intestinal tract. These represent routine consecutive admissions of 69 patients with lymphomas, 8 with osteogenic sarcoma, 8 with cancer of the pancreas, 20 with cancer of the breast, and 6 with cancer of the mouth.

\section{METHODS}

Vitamin assays were not made on any patient until an adequate hospital diet had been taken for at least 2 days, and in the patients who had undergone operation no tests were made during the first 4 post-operative days. All the venupunctures were made in the morning when the patients were fasting. In most instances, the vitamin $A$ and carotene levels were checked by repeated determinations.

1. Vitamin $A$ and carotene in plasma. The method employed for the measurement of vitamin A was the Carr-Price reaction, adapted for the photoelectric colorimeter by Dann and Evelyn (4) and modified for blood determinations by Clausen and McCoord (5) and by Kimble (6). It has been further modified for use as herein described.

The instrument used was the Pfaltz and Bauer fluorophotometer. Filter combinations Number 629 with peak at $6200 \AA$ and Number 635 with peak at $4400 \AA$ were used for vitamin A and carotene, respectively.

The standard curves for carotene were obtained from measurements of various dilutions of pure beta-carotene. Two different samples of carotene were employed, one manufactured by the S. M. A. Corporation and the other by the Hoffman-LaRoche Company (Figure 1).

For the vitamin A standard, the U.S.P. Reference Cod Liver Oil Number 2 was used, as well as other sources. These were first saponified and then treated as described by Koehn and Sherman (7). For the final standardization, a vitamin A concentrate, E (1 per cent, $1 \mathrm{~cm}$.) 107

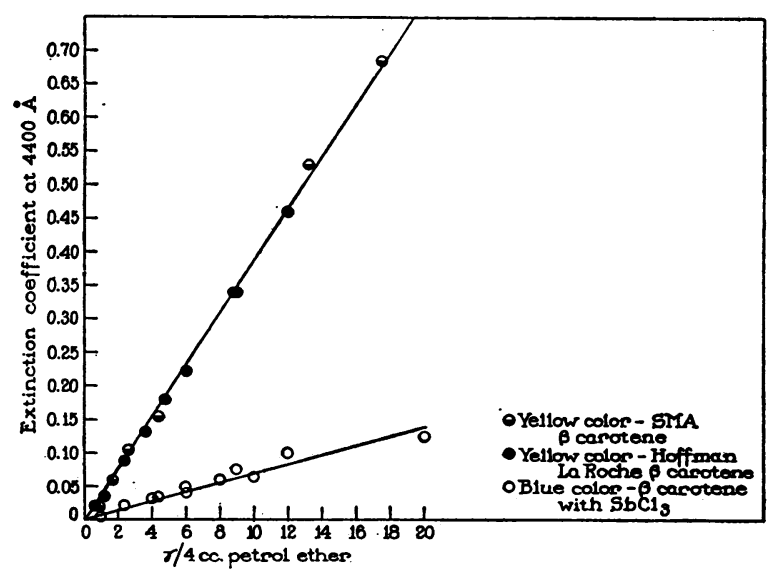

Fig. 1. Standard Curve for Carotene

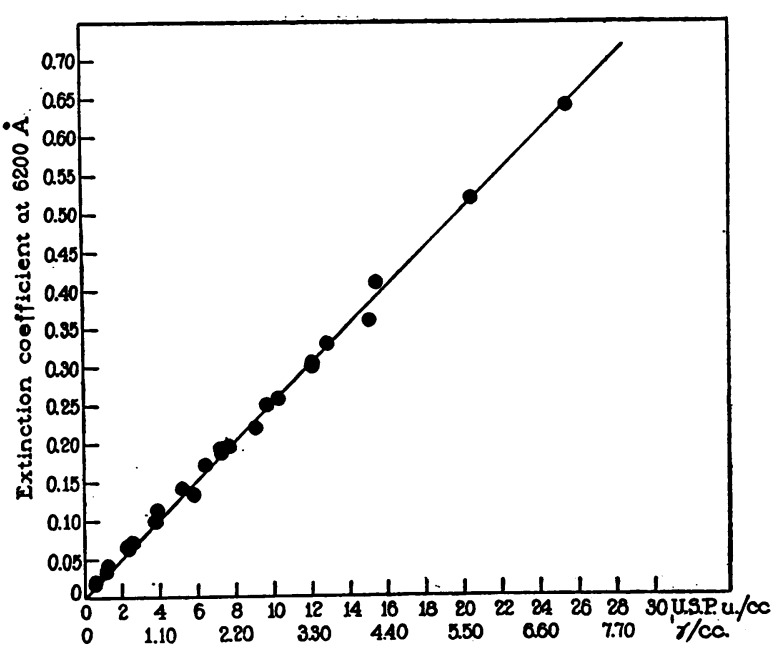

Fig. 2. Vitamin A Standard Curve-Vitamin A Concentrate E (1 PER CENT 1 cM., 107) $328 \mathrm{~m} \mu$ (Distillation Products, Inc.)

at $328 \mathrm{~m} \mu$, supplied by the Distillation Products, Inc., was employed. Because of its high potency $(224,700$ U.S.P. units per gram of oil) this oil was not saponified but was taken up directly in chloroform, in which solvent the vitamin A measurements were made. The data reported here are based on the curve computed from this standard oil (Figure 2).

Five cc. of the plasma, 5 cc. of 95 per cent alcohol, and $5 \mathrm{cc}$. of petrol ether were shaken in a stoppered centrifuge tube for 10 minutes. The layers were separated by centrifugation, and $4 \mathrm{cc}$. of the petrol ether layer were pipetted into a $10 \mathrm{cc}$. colorimeter tube $12 \mathrm{~mm}$. in diameter. The tube was stoppered and the yellow color of the carotene was read. The petrol ether was evaporated off under a stream of nitrogen and the residue taken up in 1 cc. of chloroform (reagent quality). With the tube in the instrument, $3.5 \mathrm{cc}$. of antimony trichloride reagent (225 grams $\mathrm{SbCl}_{3}$ per liter of washed chloroform) were added from a rapidly draining pipette and the maximum extinction coefficient of the blue color was measured. The extinction coefficient value was converted into U.S.P. units of vitamin A by reference to the standard calibration curves (Figures 1 and 2).

2. Thiamin in white cells. The thiamin measurements in our investigation were made by the technique developed by Atkin, Schultz and Frey (8). This method is based on the principle that the fermentation by yeast of a glucose-salt mixture to carbon dioxide is accelerated within certain limits in direct proportion to the concentration of thiamin present. This reaction is measured in a Warburg vessel under anaerobic conditions.

To obtain leukocytes, whole oxalated blood was allowed to settle and the cloudy supernatant plasma was removed and centrifuged at 3,000 r.p.m. The clear plasma was poured off and the clump of leukocytes in the bottom of the tube was taken up in a small amount of saline, mixed and transferred by a capillary pipette to a graduated 
hematocrit tube. After the hematocrit reading was obtained and the actual volume of cells calculated, the cells were diluted with isotonic saline to the optimum concentration for determinations of their thiamin content.

3. Riboflavin in the urine was determined by the method of Ferrebee (9).

\section{RESULTS}

The results of the experiments herein described group themselves naturally under three headings: (A) The levels of vitamin $\mathrm{A}$ and carotene in the plasma of normal individuals and of patients with gastro-intestinal cancer and other disorders. $(B)$ Evidence for the cause of the abnormalities discovered in these patients. (C) The effects of the administration of substances containing other vitamins on the plasma levels of vitamin $A$ in the various groups of patients.

\section{A. Vitamin $A$ and carotene levels in the plasma of normal individuals and of patients with gastro-intestinal cancer}

The mean average ${ }^{3}$ plasma vitamin $A$ of 62 normal males who were studied as controls was 170.3 U.S.P. units per $100 \mathrm{cc}$; the standard deviation $\left(\sigma_{1}\right)$ was \pm 38 , and the normal range,

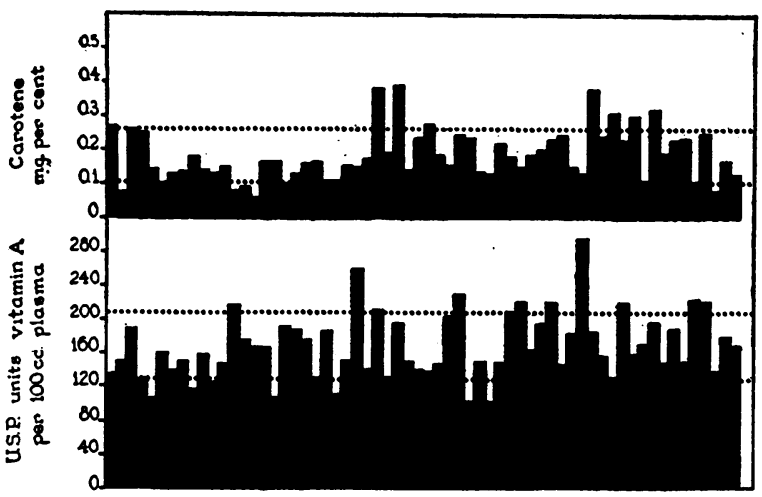

Fig. 3. Plasma Vitamin A and Carotent levels of Normal Males

therefore, from 132 to 208 U.S.P. units. The mean average carotene of this group was 0.21 mgm. per $100 \mathrm{cc}$; the standard deviation $\left(\sigma_{1}\right)$ was \pm 0.13 and the normal range from 0.09 to 0.34 mgm. per cent (Figure 3). A similar study of

\footnotetext{
${ }^{8}$ Statistical analysis was not applied to the values of vitamin $A$ and carotene in the plasmas of the various groups of patients studied because several of those groups consisted of comparatively small numbers of individuals.
}

62 normal females gave a mean average plasma vitamin A level of 149.1 U.S.P. units per 100 cc., and a standard deviation $\left(\sigma_{1}\right)$ of \pm 46 . The normal range was from 103.1 to 195.1 U.S.P. units. The mean average carotene level of the female group was $0.18 \mathrm{mgm}$. per $100 \mathrm{cc}$., the standard deviation $\left(\sigma_{1}\right) \pm 0.10$, and normal range from 0.08 to $0.40 \mathrm{mgm}$. per cent (Figure 4). As

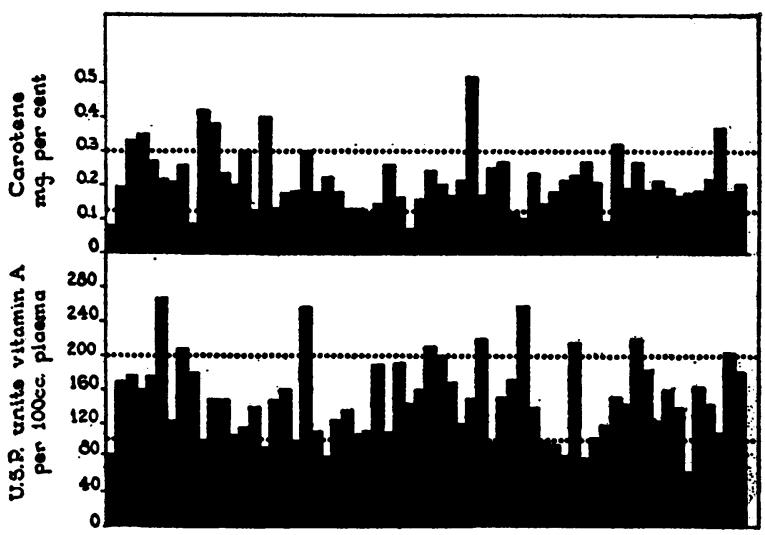

Fig. 4. Plasma Vitamin A and Carotene levels of Normal Females

long as the individuals in this study, both normal and those with cancer, remained untreated and on the same diet, their plasma levels of vitamin A never varied more than \pm 10 U.S.P. units from day to day.

The findings in the plasma of 38 males with cancer of the gastro-intestinal tract were in sharp contrast to those in normal males. The vitamin A levels ranged from 32 to 180 U.S.P. units per 100 cc. (Figure 5), and averaged 84 U.S.P. units, or about one-half the normal value. Of the 38 male patients, 34 had levels below the normal range. The average carotene of the 38 males was $0.14 \mathrm{mgm}$. per $100 \mathrm{cc}$., and ranged from 0.04 to $0.50 \mathrm{mgm}$. per $100 \mathrm{cc}$. Study of the 13 female patients in the group provided similar findings. The plasma vitamin A levels ranged from 50 to 148 U.S.P. units per $100 \mathrm{cc}$. (Figure 6), and the average was 78.5 U.S.P. units-again about half the normal value. Eleven of the 13 had levels below the normal range. The average carotene in the plasma of the 13 females was $0.135 \mathrm{mgm}$. per $100 \mathrm{cc}$., and the levels ranged from 0.05 to $0.27 \mathrm{mgm}$. per $100 \mathrm{cc}$. 

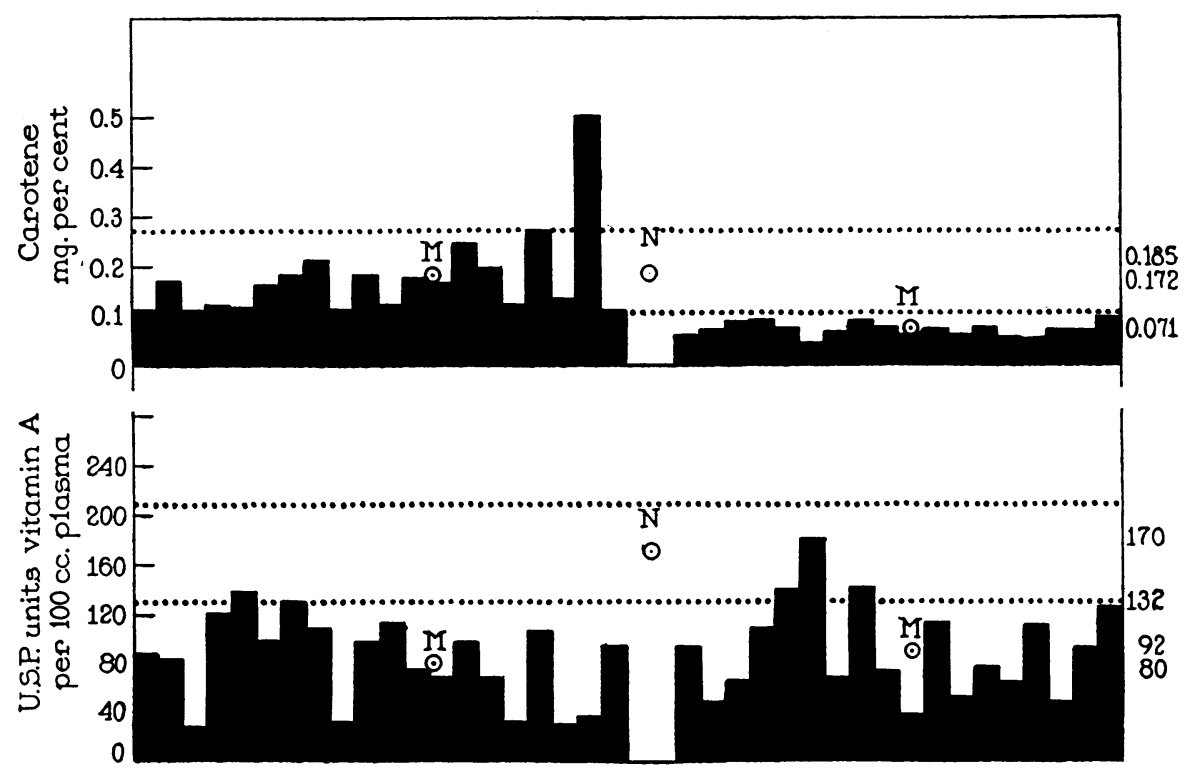

Fig. 5. Plasma Vitamin A and Carotene levels of Males with Cancer of the Gastro-intestinal Tract

Of all the 51 patients, 86 per cent had vitamin A levels below the normal range, and 96 per cent had levels lower than the average.

\section{B. Experiments to determine the cause of the low plasma vitamin A levels in plasma of patients with gastro-intestinal cancer}

The most obvious explanation of the findings of persistently low levels of vitamin $\mathrm{A}$ in the blood was that, since the patients had gastrointestinal disease, they were malnourished. If this were the case, one would expect to find a deficiency of other vitamins as well as of vitamin $\mathrm{A}$ in the plasma of these patients. Since carotene is a precursor of vitamin A, it seemed important to investigate the plasma levels of carotene, particularly in those patients who were already known to have taken restricted diets.

The dietary history of the 51 patients studied revealed that only 13 had been on diets deficient in calories, vitamins, or both. Of these 13 patients, 4 had cancer of the esophagus, 8 cancer of the stomach, and 1 cancer of the colon. Eleven were found to have plasma levels of vitamin A below the normal limits, but 4 of the 11 had plasma carotene levels within the normal range. Normal carotene levels also were found in the plasma of the 2 patients who had been on deficient diets but had normal plasma levels of vitamin A.
Of the 51 patients, 23 showed low plasma levels of carotene as well as of vitamin A. Included in this group were 7 of the 13 patients who had been on restricted diets, as described in the preceding paragraph. No further studies were made of these 23 patients, since it seemed quite possible that their dietary intake of carotenoids had been

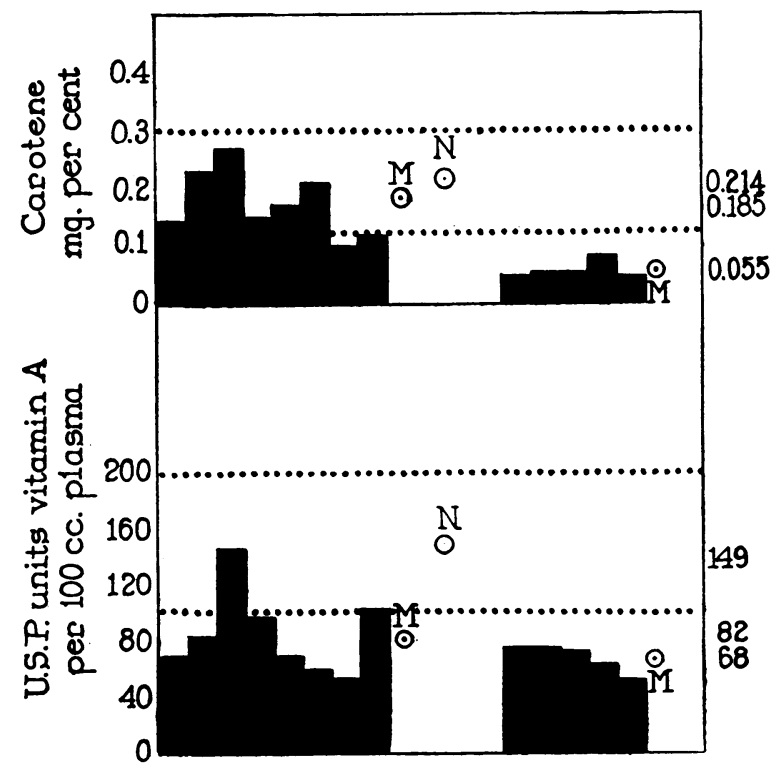

Fig. 6. Plasma Vitamin A and Carotene levels of Females with Cancer of the Gastro-intestinal Tract 
insufficient and so a simple dietary vitamin A deficiency had resulted.

The remainder of the patients, however, 28 in number, showed normal or actually elevated levels of carotene. All but 5 of them had vitamin A levels below the normal range, and all were considerably below the average. It would appear, then, that these 28 patients had neither a deficiency of carotenoids in the diet, nor malabsorption of carotenoids from the gastro-intestinal tract.

If carotene levels of the plasma are an index as to the availability of carotene for conversion to Vitamin A, then the low levels of the vitamin in these 28 patients could not be due to dietary deficiency. Bessey and Wolbach (10), however, have concluded from their studies that there is no association between the amount of carotene ingested and its level in the plasma. Hence, it was possible that the individuals with normal carotene levels who made up the second group really had ingested an insufficient amount of vitamin A. If this were true, and their dietary intake had been inadequate, it might well be reflected in a deficiency of other dietary constituents as well, and it was necessary to investigate this possibility before conclusions could be drawn as to the dietary status of the patients.

Accordingly, in 18 of the 28 patients the thiamin concentration in the leukocytes and the excretion of riboflavin in the urine were measured (Figure 7). These determinations could not be made on the remaining 10 patients of this group. To ascertain the normal values, the leukocyte thiamin of 18 normal men and women was measured, as was the riboflavin excretion in the urine of 20 normal individuals of both sexes. The average leukocyte thiamin was 90 gamma per 100 cc., and the range from 50 to 150 gamma per cent. No sex difference was observed. The amount of riboflavin excreted in the urine varied from 200 to 900 gamma per day. These values agree well with those reported by Axelrod et al. (11).

The thiamin concentration in the leukocytes of the 18 patients ranged from 52 gamma to 244 gamma per $100 \mathrm{cc}$, all within the normal limits. The average was 148 gamma per $100 \mathrm{cc}$. of leukocytes, a figure significantly higher than normal (90 gamma per $100 \mathrm{cc}$.). Why this group should have a high concentration of thiamin in their leukocytes associated with low plasma levels of vitamin $\mathrm{A}$ is unknown.

Similarly, the urinary excretion of riboflavin by the same 18 patients was within the normal limits, the range being from 175 to 1300 gamma per day, with an average of 622 gamma per day.

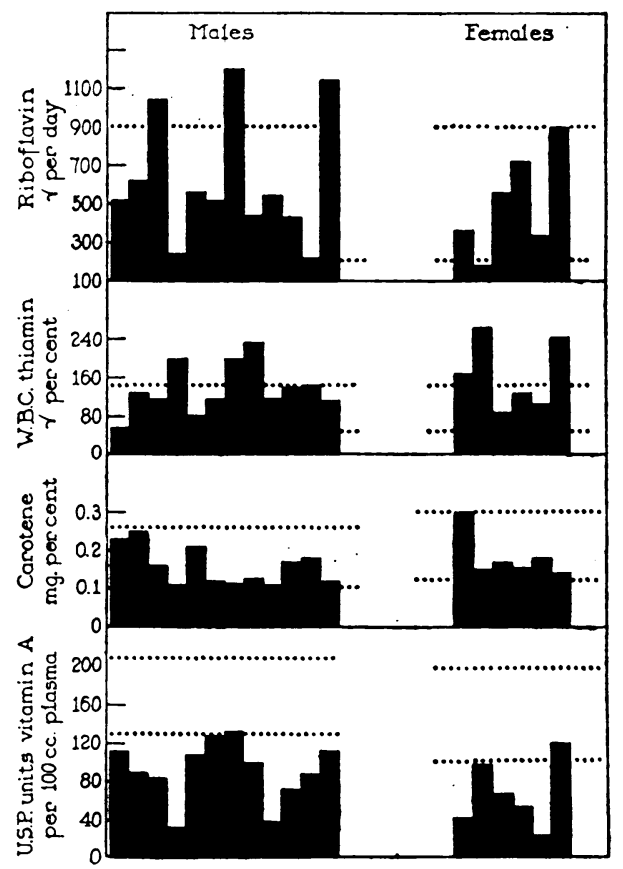

Fig. 7. Plasma Vitamin A and Carotene Levels, White Cell Thiamin and Urinary Riboflavin Levels of 19 Patients with Cancer of the Gastro-intesTINAL TRACT

Only 1 patient had an abnormally low daily output of riboflavin in the urine (175 gamma per day), but she had a normal plasma carotene of 0.15 mgm. per cent and also an exceptionally high white cell concentration of thiamin (224 gamma per 100 cc.).

From these findings, there was no evidence that the diet had been generally inadequate in the 18 patients investigated whose low plasma levels of vitamin A were associated with normal levels of carotene. One could not be entirely satisfied, however, that the normal values used for comparison were valid as controls for this group of patients. Since the normal individuals examined differed widely in age, race, and economic background from the patients, it seemed possible that 
these factors, rather than the disease from which they suffered, might be responsible for the low levels of vitamin $A$ in the plasma of the patients. It was important to establish, therefore, whether individuals of the same age, race, and economic status as the patients also would have low levels of plasma vitamin A.

As a preliminary step, it seemed feasible to test groups of patients similar in social and economic background to those with gastro-intestinal cancer. If levels of vitamin $A$ as low as those in the patients with gastro-intestinal cancer were found in these individuals, a further check would be provided.

Of 20 patients with leukoplakia of the oral mucosa, however, only 3 (15 per cent) showed such levels, and 2 of these 3 had been on grossly deficient diets. None of the 20 was known to have syphilis or associated cancer. Similarly, of the 13 patients with atrophic gastritis, none showed abnormally low plasma levels of vitamin A. All of the 13 had symptoms referable to their disease, and 4 had been on grossly inadequate diets.

No further proof seemed necessary, therefore, to establish the fact that race, age, and economic background were not responsible for the low levels in the patients with gastro-intestinal cancer. These findings, furthermore, indicate that patients bearing supposedly precancerous lesions, namely oral leukoplakia and atrophy of the gastric mucosa, do not have low plasma levels of vitamin A.

From the evidence at hand, it was only possible to conclude that the patients with gastrointestinal neoplasm were in some way unable to distribute normally the vitamin A taken in with the diet. Such an abnormality might be due simply to the presence of a lesion which interfered with the absorptive power of the gastro-intestinal tract, quite irrespective of its malignant nature. Were this the case, patients with benign disorders of the intestinal tract marked by persistent vomiting or diarrhea should show similarly low levels of plasma vitamin A.

Fourteen patients with benign lesions were examined. Eight had peptic ulcers, 2 severe ulcerative colitis, 2 had long-standing active sprue and 2 mucous colitis. The 8 patients with peptic ulcer had had nausea, vomiting and weight loss for several months at the time of examination. The remaining 6 had had diarrhea and weight loss for from 1 to 10 years. There were 6 males and 8 females in the group. The 6 males had plasma levels of vitamin A which ranged from 102 to 212 U.S.P. units per $100 \mathrm{cc}$., and averaged 180 U.S.P. units per $100 \mathrm{cc}$, or slightly above the

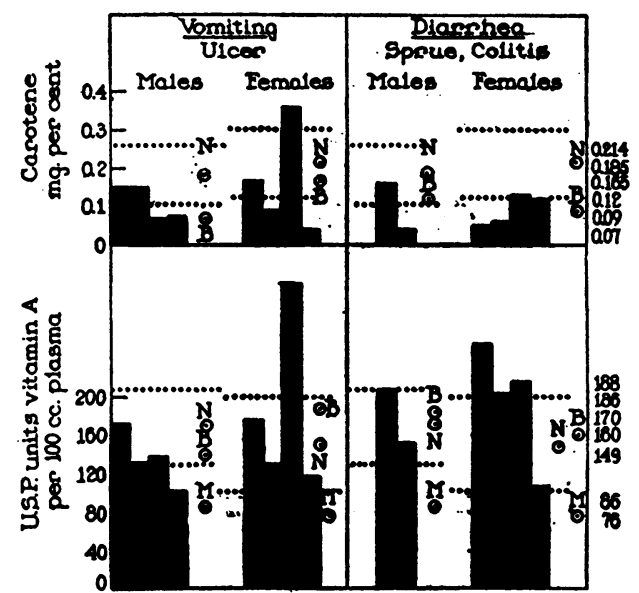

Fig. 8. Plasma Vitamin a and Carotene levels of 14 Patients with Benign Lesions of the GastroINTESTINAL TRACT

normal average for males. The 8 females had plasma vitamin A levels which ranged from 104 to 320 U.S.P. units per $100 \mathrm{cc}$. and averaged 190 U.S.P. units, a figure somewhat higher than the normal average for females. Of the 14 patients, only 2 males had plasma vitamin A concentrations below the normal range (Figure 8 ).

\section{Effect of administration of vitamin $A$ on plasma levels of that substance in patients with gastro-intestinal cancer}

From the results of the study described above, it appeared probable that the low levels of vitamin $\mathrm{A}$ in the plasma of the patients with gastro-intestinal cancer were due neither to poor dietary intake nor to functional disturbance of the gastrointestinal tract, but rather to lack of absorption or to some metabolic disturbance which prevented the vitamin $A$ ingested from appearing in the plasma.

In order to investigate this possibility further, the effect of administration of vitamin $A$ on the plasma levels of these patients was compared with 
the effect of the administration of the same amounts of vitamin $A$ to patients with similarly low plasma levels associated with other disorders. Eight patients with low plasma vitamin A levels associated with lesions other than gastro-intestinal tract cancer were given from 50,000 to 150,000 units daily of vitamin $A$ for from 6 to 20 days. The vitamin was administered parenterally to 5 and orally to 3 . Three of the patients had welladvanced cancer of the pancreas, 2 had hepatic cirrhosis, 1 pyloric obstruction secondary to a duodenal ulcer, 1 chronic myeloid leukemia, and 1 an osteogenic sarcoma. In every one the ad- to the patients with low plasma levels associated with lesions other than gastro-intestinal tract cancer. The vitamin was administered orally to 1 patient, parenterally to 6 , and both orally and parenterally to 1 . In 5 of the 8 patients the low vitamin A levels were associated with normal plasma concentrations of carotene. Only 1 patient previously had been on a deficient diet. In only 2 of the 8 patients did the plasma level of vitamin A rise following the administration of that substance. Neither of these had been on grossly deficient diets, and both had plasma carotene levels within the normal range. In the other

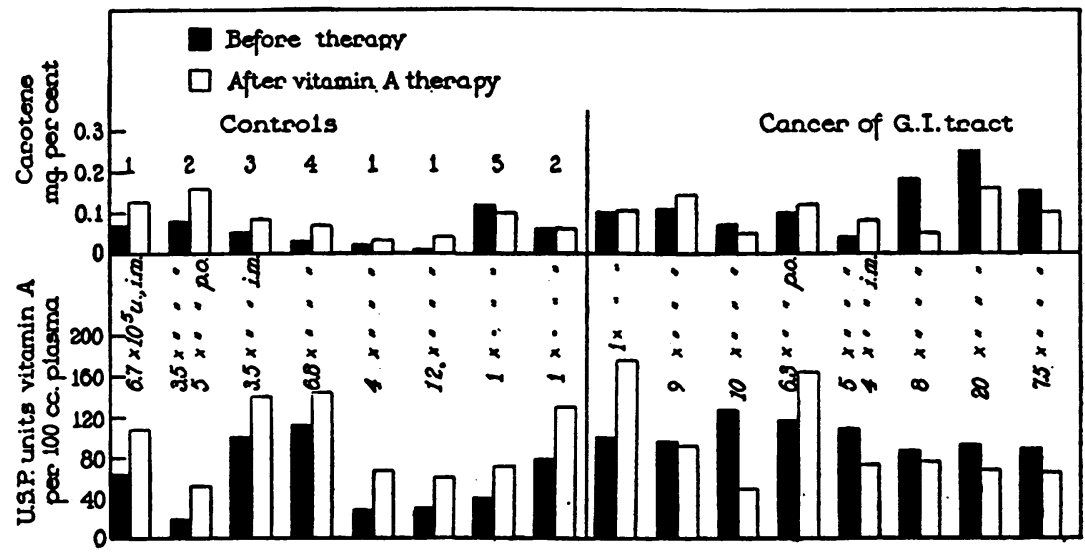

Fig. 9. Effect of Vitamin A Supplement on the Levels of Vitamin A and Carotene in the Plasma of a Control Group and of Those with Cancer of the Gastro-intestinal Tract

1. Cancer of pancreas. 2. Cirrhosis. 3. Peptic ulcer. 4. Leukemia. 5. Osteogenic carcinoma.

ministration of vitamin A was followed by a rise in the plasma levels of from 40 to 180 per cent above the original levels (Figure 9). The average rise was 90 per cent. Further evidence that the amount of vitamin administered was sufficient to raise a level, low because of simple deficiency, is provided by the studies of Steininger (12) and of Murrill (13) who demonstrated that the low plasma levels of vitamin A of normal individuals on vitamin A-deficient diets could be restored to normal by the administration of from 20,000 units (12) to 400,000 units (13) of vitamin A.

In contrast to the findings just described were the results of a similar study in patients bearing cancer of the gastro-intestinal tract. Eight male patients with low plasma concentrations of vitamin A were given the same amounts of the vitamin, over periods of from 7 to 20 days, as were given
6 patients the plasma vitamin A levels after administration were from 5 to 33 per cent less than they had been before, and the average fall was 28 per cent (Figure 9).

In neither the control group nor the group with gastro-intestinal cancer did the administration of vitamin A effect any consistent change in the concentration of carotene in the plasma.

It appeared, then, that in the patients with gastro-intestinal tract cancer some specific disorder was present which prevented the normal distribution of vitamin $\mathrm{A}$ by the patients, even though amounts were made available which could raise the low levels in patients with other disorders. However, it was also possible that the rate of destruction or excretion of the vitamin was abnormally high. No methods for the investigation of these possibilities were at hand. 


\section{Plasma levels of vitamin $A$ in patients who had had cancer of the gastro-intestinal tract removed}

In order to determine whether or not the low plasma levels of vitamin A were contingent upon the actual presence of cancer in the organism, the concentration of the vitamin was determined in the plasma of 19 patients who had had gastrointestinal cancer surgically removed. Eleven of the patients were males and 8 females. Twelve originally had had cancer of the stomach, and 7 had cancer of the large bowel. The patients were examined from 3 months to 10 years after operation, and at the time of examination were believed to be free of neoplastic disease. Of the 19 patients, 3 had been on grossly deficient diets for at least 4 months before the vitamin A levels were determined.

Of the 11 male patients, 4 had plasma vitamin A levels below the normal range, but the average was 176 U.S.P. units per 100 cc., only slightly more than the average for normal males (170.3 U.S.P. units). Of the 8 females, only 2 had a plasma vitamin A level below the normal range, and the average was 145 U.S.P. units per $100 \mathrm{cc}$., a figure slightly less than the average found in normal females (149.1 U.S.P. units) (Figure 10).

It would appear, then, that the incidence of low plasma levels of vitamin $A$ in patients who have had gastro-intestinal cancer surgically removed is considerably less than in patients with the cancer still present.

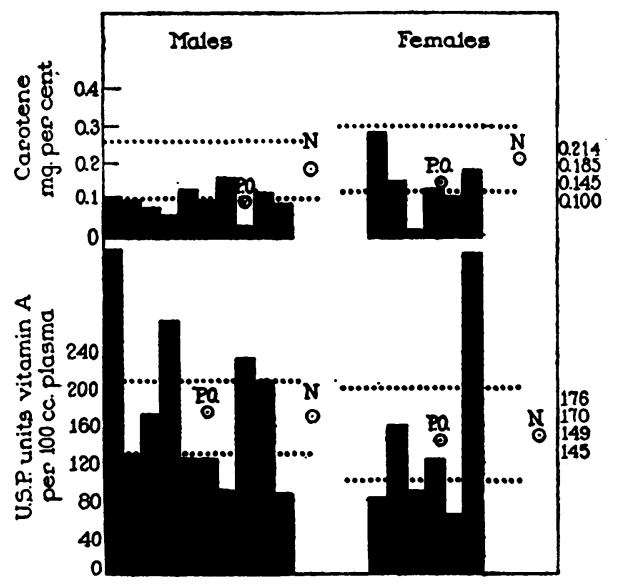

Fig. 10. Plasma Vitamin A and Carotene Levels in Patients Who Had Cancer of the Gastro-intestinal Tract Removed

\section{Plasma levels of vitamin $A$ in patients with malignant diseases other than gastro- intestinal cancer}

It was next important to discover whether low plasma vitamin A levels were confined to individuals with cancer of the gastro-intestinal tract and, accordingly, a group of patients with malignant neoplasms of other types was examined.

Of 48 patients with leukemia, the average plasma vitamin A level of 34 males was 119 U.S.P. units, and the average vitamin A level of 14 females was 113 U.S.P. units. Of the 48 patients, 24 , or 50 per cent, had plasma levels below the normal range. Of 21 patients with Hodgkin's disease, the average plasma vitamin A level of 11 males was 63.3 U.S.P. units, and the average level of the 10 females was 75.9 U.S.P. units. Of the whole group, 18 , or 84 per cent, had levels below the normal range. Of 9 patients with cancer of the head of the pancreas, the average for the 6 males was 115 U.S.P. units, and for the 3 females 101 U.S.P. units. Five of the 9 patients had levels below the normal range. Of 6 patients with bone sarcoma, 3, all males, had plasma levels of vitamin A below the normal limits.

In sharp contrast were the findings in patients with mammary and oral cancer. Only 1 of the 20 women with cancer of the breast, and none of the 8 patients with intra-oral neoplastic disease, had plasma levels below the normal range.

These findings are of interest, since they indicate that low levels of vitamin $\mathrm{A}$ in the plasma are not specific for gastro-intestinal cancer but also may be found associated with other forms of malignant disease.

\section{The effect of the administration of substances containing other vitamins on the plasma levels of vitamin $A$ in patients with gastro-intes- tinal cancer and with other diseases}

Since the administration of vitamin $A$ in amounts adequate to raise the low levels of the vitamin in the plasma of patients not bearing gastro-intestinal cancer had only an irregular effect on the plasma levels in patients with this disease, the effect of the administration of other vitamins was studied. 


\section{Yeast}

As a part of a general therapeutic regime to prepare the patients for operation, 90 grams of Fleischmann's 20-40 granular Brewer's yeast were fed daily, over periods of from 4 to 32 days, to 17 patients with gastro-intestinal cancer. This yeast was shown to be free of both vitamin A and carotenoids both by the Carr-Price reaction and by biological assay. One of the 17 patients previously had been given 750,000 U.S.P. units of vitamin A parenterally, and that amount of the vitamin had not elevated the originally reduced plasma level.

All of the 17 patients, after yeast therapy without vitamin A, showed a substantial elevation of their plasma levels of vitamin A. Fourteen of the 17 patients at the outset had plasma levels below the normal range. The average rise of vitamin $\mathrm{A}$ in the plasma of the 17 patients was 215 per cent, and the range was from 12 to 835 per cent (Figures 11 and 12).

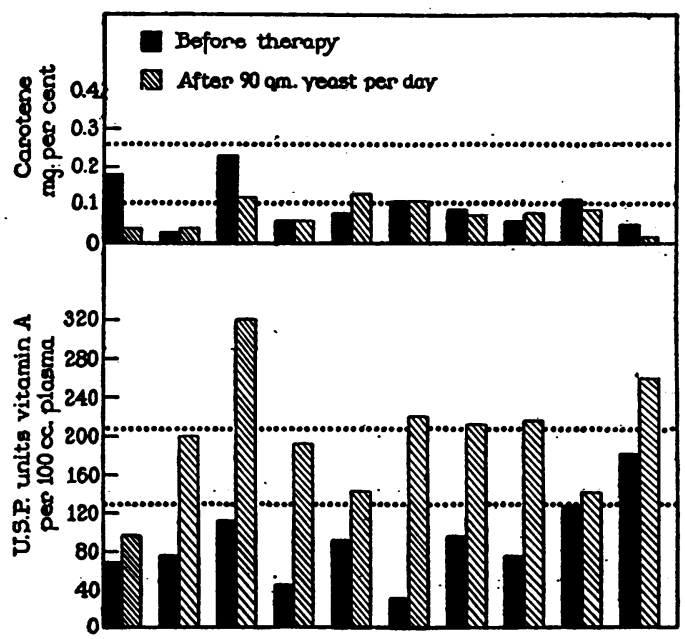

Fig. 11. Plasma Vitamin A and Carotene levels of Males with Cancer of the Gastro-intestinal Tract Before and After Yeast Therapy

In contrast to the effect on the plasma concentration of vitamin A was the lack of any consistent change in the plasma levels of carotene after the administration of yeast. In 6 of the 17 treated patients the carotene rose, in 7 it fell, and in 4 there was no change whatsoever.

In 4 instances, after the yeast had effected a rise in the levels of vitamin A in the plasma, the therapy was discontinued. The withdrawal was

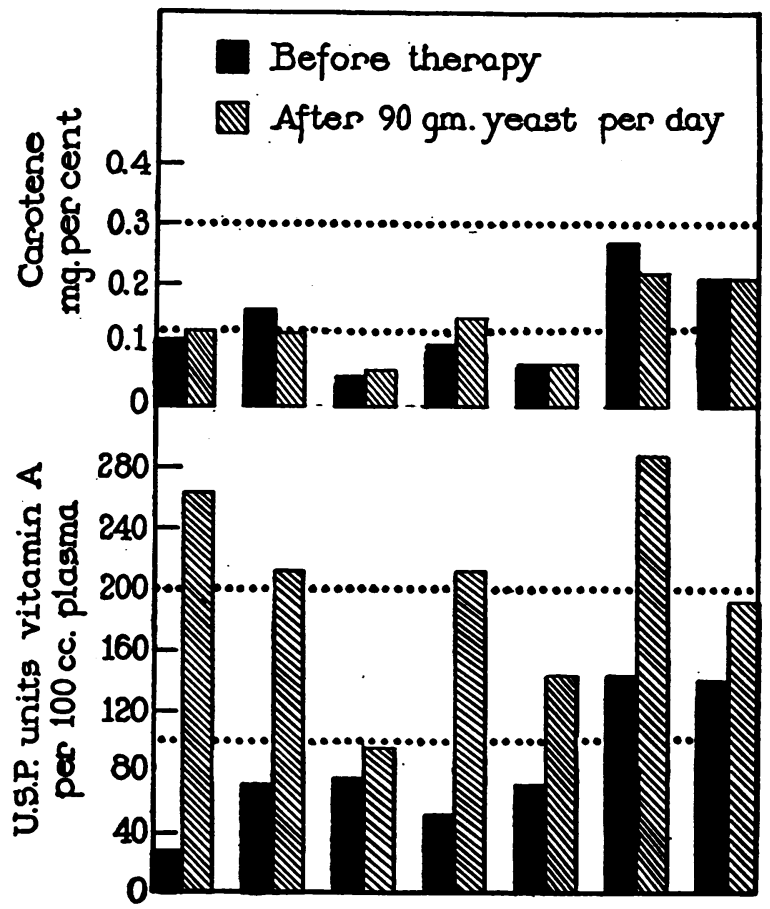

Fig. 12. Plasma Vitamin A and Carotene levels of Females with Cancer of the Gastro-intestinal Tract Before and After Yeast Therapy

followed in each instance by a drop in the vitamin A levels. The course of 1 of these patients, G. B., is graphically depicted in Figure 13 . In this patient a second rise was obtained when the treatment was reinstituted.

Similar elevation of low vitamin A levels to the normal range followed the administration of

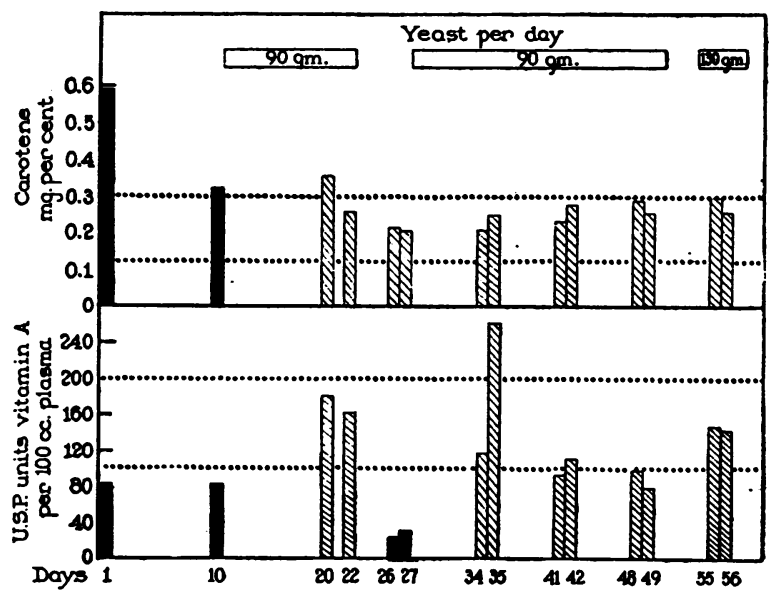

Fig. 13. Plasma Vitamin a and Carotene levers of Patient G. B., 9 , with Cancer of the Colon BeFORE AND AFter YEAST THERAPY 
yeast to 13 patients who had such diseases as hepatic cirrhosis, retinitis pigmentosa, cholecystitis, polyposis coli, and cancer of the head of the pancreas. The moderately reduced level of vita$\min \mathrm{A}$ in the plasma of a patient with a peptic ulcer was also restored to the normal range after the patient was fed yeast. There was no consistent effect on the plasma carotene of this group (Figure 14).

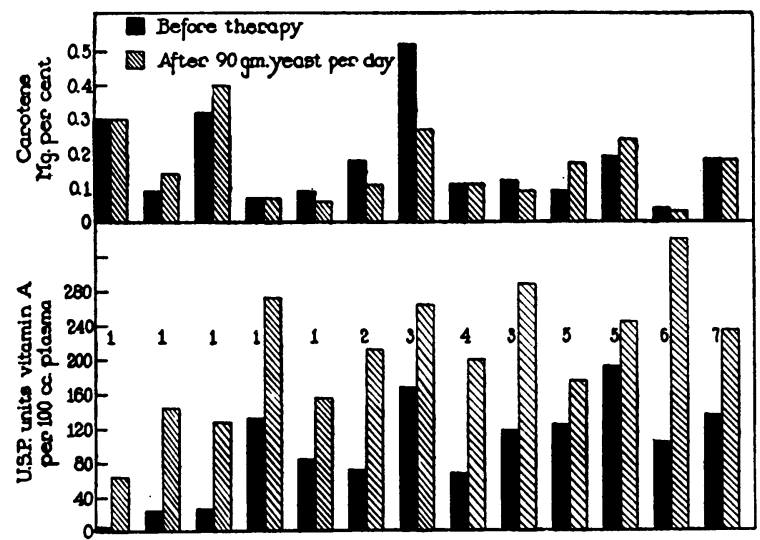

Fig. 14. Effect of Yeast on Plasma Vitamin A and Carotene Levels in Patients with Diseases other than Cancer of the Gastro-intestinal Tract

1. Cirrhosis. 2. Nyctalopia. 3. Duodenal ulcer. 4. Cholecystitis. 5. Gastric ulcer. 6. Cancer of pancreas. 7. Polyposis.

On the other hand, no elevation of reduced plasma levels of vitamin A followed the administration of yeast to 2 patients with Hodgkin's disease and to 3 patients with chronic leukemia. The normal plasma vitamin A and carotene levels of 2 normal individuals also were unaffected after the administration of 90 grams of yeast each day for 1 week. ${ }^{4}$

\section{Lipocaic and choline}

The ability of yeast to raise the plasma levels of vitamin $\mathrm{A}$ in patients with gastro-intestinal tract cancer was considered to be due to one or some combination of the following causes: (1) The yeast aided the absorption of ingested carotenoids through the intestinal wall. (2) It contained a substance with lipotropic activity which caused the release into the blood stream of fat-

\footnotetext{
4 The authors are indebted to the Standard Brands, Inc., for supplying the yeast used in this investigation.
}

soluble vitamin A and other fat-soluble compounds from the liver or from other fat depots of the body. (3) The yeast corrected some abnormality which prevented the normal deposition of the vitamin.

The first possibility has been covered by the observation that even the parenteral administration of vitamin A usually did not elevate the low levels of the vitamin in the plasma of patients with gastro-intestinal cancer.

To examine the second possibility, two materials with known lipotropic activity were administered to patients. The first material was lipocaic, ${ }^{5}$ and its use was suggested by Dr. Charles Best of Toronto. It is a pancreatic extract prepared after the method of Dragstedt (14). The second lipotropic substance tested was choline chloride. ${ }^{6}$

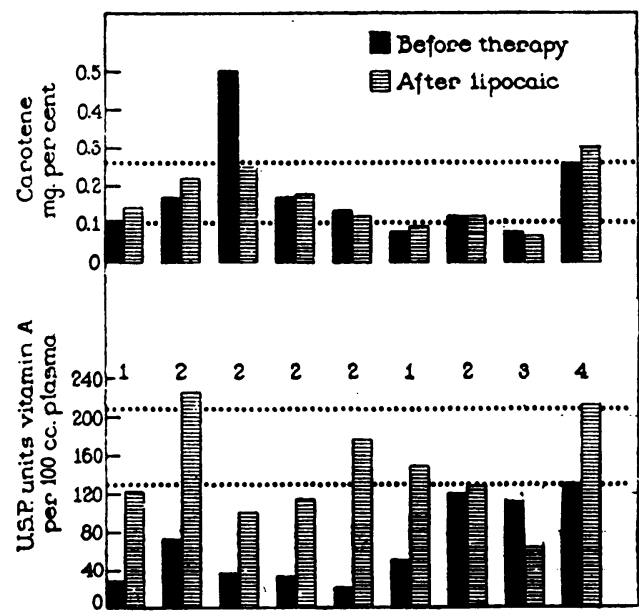

Fig. 15. Plasma Vitamin A and Carotene levels of Males Before and After Lipocaic

1. Cancer of colon. 2. Cancer of stomach. 3. Cancer of pancreas. 4. Normal.

(a) Lipocaic. Two patients with rectosigmoid cancer and 5 with gastric cancer were fed 5 grams daily of lipocaic for from 4 to 18 days. All had low plasma levels of vitamin A before therapy was instituted, and in 6 of the 7 cases, therapy effected substantial, sustained increase of the concentration of the vitamin in the plasma. The seventh case showed only a slight increase after

${ }^{5}$ Supplied through the courtesy of the Eli Lilly Company.

B Supplied through the courtesy of the S. M. A. Corporation. 
therapy. The average rise in the plasma of the 7 patients treated with lipocaic was 270 per cent, and the range was from 6 to 710 per cent (Figure 15). The results in 2 of these patients are shown in Figures 16 and 17.

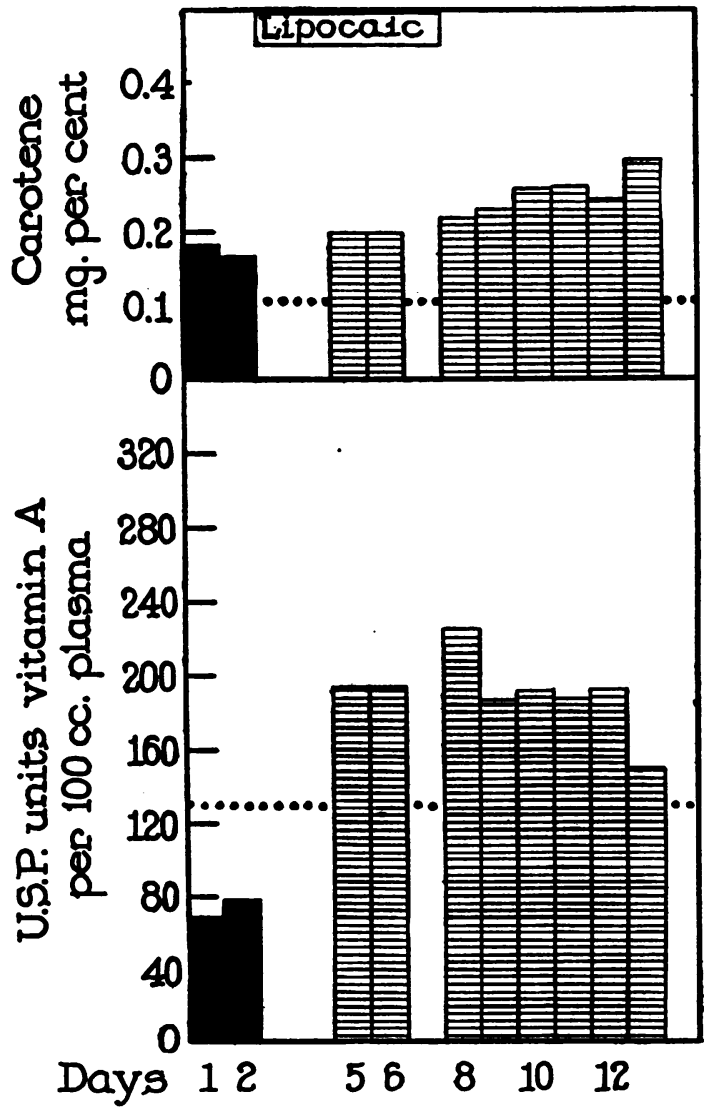

Fig. 16. Plasma Vitamin A and Carotene levels of Patient S. T., d, with Cancer of the Colon Before aNd After Lipocaic Therapy

Five grams of lipocaic were fed each day for 6 days to 2 normal individuals. After the administration, the plasma levels of vitamin A rose in one individual from 126 to 212 U.S.P. units, and in the other from 140 to 215 U.S.P. units.

Five grams of lipocaic were administered each day for 4 days to a patient with cancer of the pancreas. After the administration of this substance, his plasma level of vitamin A fell from 112 to 64 U.S.P. units.

(b) Choline chloride. The lipotropic effect of this substance now has been demonstrated by several workers $(15,16)$.

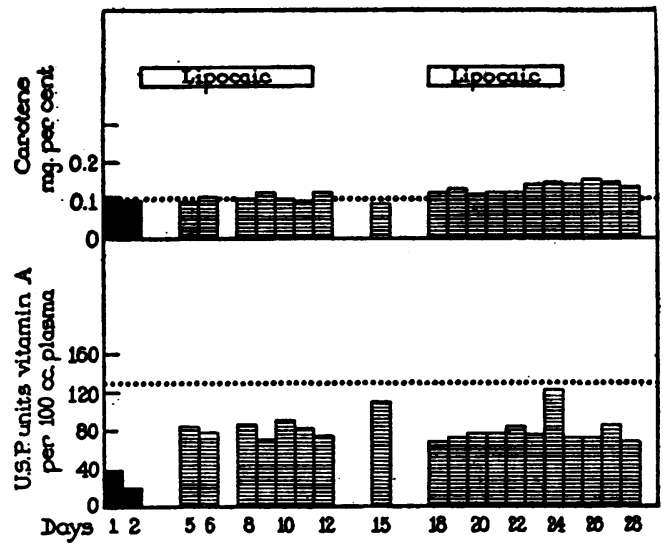

Fig. 17. Plasma Vitamin A and Carotene levels of F. C., $\delta$, Before and After Lipocaic Therapy

Six patients with gastric cancer and 1 with rectal cancer were fed 1.5 grams of choline chloride each day for 3 days. Five of the 6 patients had abnormally low plasma vitamin A levels when the administration of choline was begun. In all 6 patients the therapy effected substantial increases in the plasma levels of the vitamin. The average rise after choline chloride was 73 per cent, and the range was from 30 per cent to 140 per cent (Figure 18).

One and a half grams of choline chloride were fed each day for from 3 to 5 days to 5 patients with such diseases as retinitis pigmentosa, peptic ulcer, cancer of the bronchus, sarcoma of the

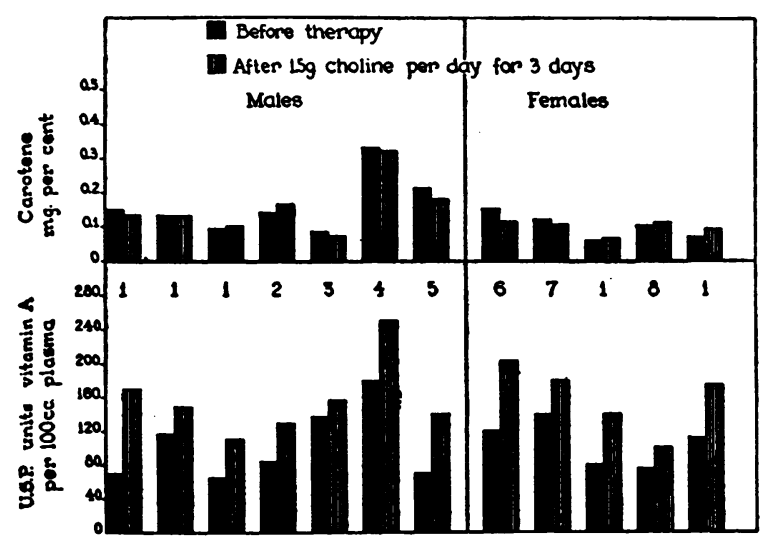

Fig. 18. Plasma Vitamin a and Carotene levels in Patients Before and After Choline Therapy

1. Carcinoma of stomach. 2. Carcinoma of bronchus. 3. Hemolytic anemia. 4. Retinitis pigmentosis. 5. Carcinoma of rectum. 6. Sarcoma of stomach. 7. Peptic ulcer. 8. Gastritis. 
stomach, and hemolytic anemia. In every instance the administration of choline chloride effected a rise in the plasma levels of vitamin A. The average rise was 98 per cent (Figure 18), and the range was from 15 per cent to 300 per cent.

Nine normal individuals also were given 1.5 grams of choline chloride each day for 3 days. After the administration of this substance, the vitamin A levels in the plasma of all 9 individuals increased from 6 per cent to 90 per cent. The average rise was 46 per cent (Figure 19).

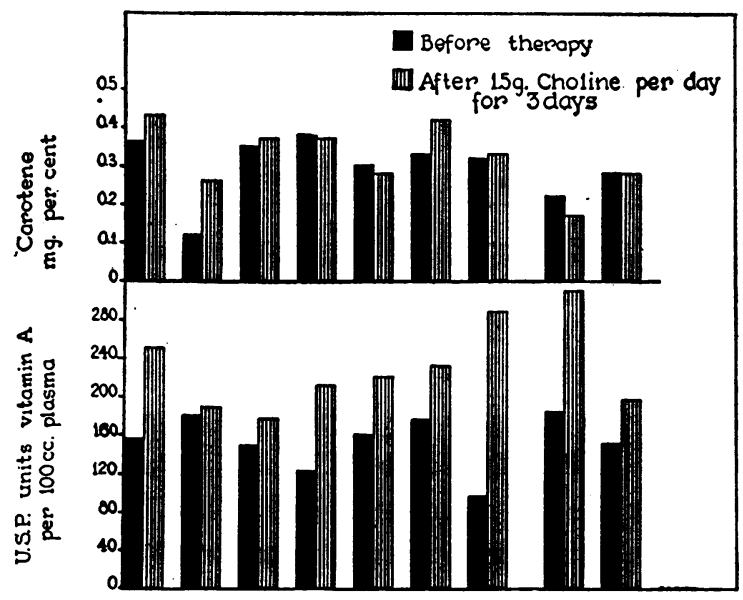

Fig. 19. Plasma Vitamin A and Carotene Levels in Normal Adults Before and After Choline

It appears from the evidence that the effect of yeast, and that of lipocaic and choline, is somewhat similar as far as the plasma levels of vitamin $\mathrm{A}$ in the patients studied are concerned. Further investigation will be required to establish the identity, or lack of identity, of the effective constituents of the three materials tested.

Experiments are now in progress to test the third possible action of the yeast, namely that the administration of the yeast corrected an abnormality which prevented normal storage of the vitamin $\mathrm{A}$. The vitamin $\mathrm{A}$ and carotene contents of liver biopsies of patients with and without gastro-intestinal cancer are now being determined. Half of these patients are fed yeast or vitamin A previous to laparotomy.

\section{DISCUSSION}

All of the vitamin A determinations in this communication were based on the Carr-Price reaction. This reaction is not specific for vitamin
A alone, since certain plant pigments and carotene are known to give a blue color reaction with antimony trichloride (17). However, the Carr-Price reaction is the most satisfactory chemical method for the quantitative estimation of vitamin $\mathrm{A}$ and carotene (18), and it is generally accepted that the amount of blue color produced by the reaction of the vitamin with antimony trichloride is proportional to the amount of vitamin A present (7). Koehn and Sherman (7) found that values arrived at by biochemical assays were in excellent agreement with the photoelectric measurements of the Carr-Price reaction products of vitamin $\mathrm{A}$ in cod liver oil. From their studies they obtained a factor of 2120 with which to convert $E$ (1 per cent, $1 \mathrm{~cm}$.) into U.S.P. units of vitamin A per gram of oil.

Barthen and Leonard (19), furthermore, found that the biological assay of vitamin A in fish oils gave values which checked closely with those obtained by direct spectroscopic measurements of the same samples. These workers arrived at a conversion factor of 2222 .

Baxter and Robeson (20) have prepared crystalline vitamin A. Spectrophotometric measurements of the crystalline vitamin itself and of the blue Carr-Price reaction product of it gave values within 3 per cent of each other. These authors compared the vitamin A potency of fish oil preparations both by bio-assay and by spectrophotometry, and calculated a factor of 2100 by which one could convert the spectrographic extinction coefficient into U.S.P. units. This last conversion factor has been confirmed (21).

There have been no reports in the literature of direct spectrophotometric measurements of those substances in blood plasma which give the blue color with the Carr-Price reagent. At our suggestion, Dr. Embree and Dr. Shantz of the Distillation Products, Inc., analyzed a sample of plasma for its vitamin content. ${ }^{7}$ This sample was first assayed in this laboratory by the Carr-Price reaction, and was found to contain 75 U.S.P. units of the vitamin. Spectrophotometric measurements of the antimony trichloride reaction product then indicated that the sample contained 72 U.S.P. units.

7 This work was done by the Vitamin Distillation Corporation through the courtesy of Dr. N. D. Embree. 
The same sample of plasma was treated by the technique of Embree (22) to cyclize any vitamin A which may have been present. The plasma treated by their technique showed an absorption spectrum after treatment which was typical of cyclic vitamin $A$, and the amount of cyclic vitamin A formed (72 U.S.P. units) corresponded very closely with the amount of vitamin $A$ assumed to be present on the basis of the Carr-Price reaction previously performed on the same sample of plasma; namely, 75 U.S.P. units.

Since the various conversion factors obtained by different groups of investigators have checked so closely, and since the cyclic vitamin A measured in the plasma could have been formed only from preexisting vitamin $A$, it is evident that the interpretation of the results of the Carr-Price technique used in the studies here reported rests on a sound basis.

It was important to determine whether or not the apparent increase of vitamin A in the plasma, effected by the administration of yeast and lipocaic, was due to vitamin $\mathrm{A}$ or other carotenoids. When the Carr-Price technique was applied to yeast and lipocaic, the final extracts gave no blue color. It therefore seemed unlikely that the increase of the Carr-Price reactants of the plasma of patients treated with these materials was due to the administration of any carotenoids. Choline chloride does not give the Carr-Price reaction.

Both yeast and lipocaic contain fractions which can reduce the fat content of the fatty liver of animals treated with biotin (23). The fatty livers of pancreatectomized animals, controlled with insulin and glucose, and of animals on high fat diets, can be prevented, and the fat content of the already pathological liver reduced, when the animals are fed lipocaic $(24,25)$, or yeast $(26)$. Choline chloride also can prevent the deposition of fat into the livers of animals on high fat-low protein diets (27) and reduce the lipid content of the fatty liver (28). Choline exists in both yeast (29) and lipocaic (30) and therefore the lipotropic effects of those materials could have been due to their content of choline.

It is possible, therefore, that the lipotropic properties of yeast, lipocaic and choline, which demobilize lipoids from the liver, might be responsible for the increase in the content of fat-soluble vitamin $A$ in the plasma after the administration of these lipotropic substances. This possibility is based on the assumption that the lipoids in the fatty liver may withhold from the blood the fatsoluble vitamins-an assumption as yet unproved by experiment. Should this be the explanation of the increased levels of vitamin $A$ in the plasma after the yeast and lipocaic therapy, then there must come a time when continued treatment will deplete all the hepatic store of vitamin A. Continued therapy, therefore, should be unable to maintain the increased plasma concentration of the vitamin. This stage may have been reached in the case of G. B. (Figure 13) cited in the previous section. The concentration of vitamin A had been increased in the plasma of that patient by feeding 90 grams of yeast per day, but after 20 days of yeast therapy the plasma level of the vitamin once again fell to near its original value.

Although the Carr-Price reactants of the plasma appear to be entirely vitamin $A$, it would be important, nevertheless, to determine whether or not the increase of plasma vitamin A after yeast therapy represents an apparent or true increase. Plans for such an experiment are in progress in collaboration with Dr. Embree of the Vitamin Distillation Corporation.

It also would be interesting to correlate the plasma levels of the Carr-Price reactants with an improvement of a physiologic function dependent upon vitamin $A$. Both good and bad correlations of the plasma levels of vitamin A with visual dark adaptation have been reported $(31,32)$. A recent study which employed the Hecht adaptometer (33) concluded that the plasma vitamin A level of an individual was not a good index of his ability to effect dark adaptation.

The explanation for the observation that patients with gastro-intestinal cancer have low plasma levels of vitamin A was considered at first to be an insufficient intake of carotenoids. This was thought to be due possibly to a deficiency of carotenoids in the diet or to malabsorption of carotenoids from the gastro-intestinal tract. However, as previously indicated, deficient diets or a deficient intake of carotenoids could not explain the low plasma vitamin A levels in the 51 patients with gastro-intestinal cancer. This was demonstrated by the following observations: (1) Seventy-five per cent of the patients had satisfactory dietary histories. (2) Only 15 per 
cent of a control group of patients with oral leukoplakia, and none of a control group with atrophic gastritis who had been on a similar diet, had reduced levels of plasma vitamin A. (3) Fiftyfive per cent of the 51 patients had normal plasma levels of carotene. (4) Of the 28 patients who had low plasma levels of vitamin A and normal plasma carotene levels, 18 were examined further for thiamin or riboflavin deficiency. None of the 18 were deficient in thiamin and only 1 was deficient in riboflavin. (5) Of great importance was the observation that the parenteral administration of large amounts of vitamin A was unable to raise the plasma level of the vitamin in 6 of 8 patients with gastro-intestinal cancer, but was able to do so in all of 8 patients with vitamin A deficiency who were used as controls. This latter group included 6 patients with malignant neoplastic disease other than gastro-intestinal cancer and 2 with non-neoplastic disorders. It has been demonstrated by Steininger (12) and by Murrill (13) that normal individuals on low vitamin $\mathrm{A}$ diets develop low levels of the vitamin in their plasma. The administration of from 20,000 to 400,000 units of vitamin A promptly restored to normal the plasma levels of the vitamin in the normal individuals.

It is unlikely that malabsorption of fat-soluble vitamins could have been responsible for the low levels of vitamin $A$ in the plasma of patients with gastro-intestinal cancer. Only 6 of the 51 patients presented either had diarrhea or suffered from persistent vomiting. It is true that in those 6 patients the diarrhea or vomiting might have prevented adequate absorption of vitamin A from their gastro-intestinal tracts. If this were the reason for the low vitamin A concentration in the plasma of those 6 patients, then low concentrations of the vitamin should have been expected to exist in the plasma of other patients bearing benign gastro-intestinal lesions and who had a comparable degree of diarrhea or vomiting. However, of 14 patients with benign gastro-intestinal lesions, 6 had severe diarrhea and 8 had suffered from persistent vomiting, but only 2 of these 14 had a plasma vitamin A level below the normal range.

It was evident, then, that patients with gastrointestinal cancer could have low levels of vitamin $\mathrm{A}$ in their plasma despite their adequate ingestion and absorption of the vitamin. Then, could the low plasma levels of vitamin A in these patients be due to an inability to store the vitamin or to convert it from its precursor carotenoids?

Under normal conditions about 90 per cent of the vitamin A in the human body is stored in the liver $(34,35)$. It has been demonstrated that damaged livers have difficulty in storing other substances; namely, glycogen (36), labile protein (37), and the anti-pernicious anemia principle (38). It is thus plausible that the damaged liver might no longer be able to store vitamin $A$. It previously has been pointed out that the hepatic store of vitamin A in patients with portal cirrhosis and with acute or chronic liver atrophy is considerably reduced (39 to 42 ). Undoubtedly, the liver is intimately concerned with the metabolism of vitamin A since, not only does it control the distribution of the vitamin in various parts of the organism (34), but it also converts carotene through an enzymatic reaction into the vita$\min (43,44)$. It appears that, as other hepatic functions are lost in the damaged liver, this conversion of carotene into vitamin $\mathrm{A}$ also is impaired $(45,46)$.

It was important, therefore, to ascertain whether or not patients bearing cancer of the gastro-intestinal tract have any anatomical or physiological derangement of their livers. The most likely explanation for hepatic derangement in these patients would be metastatic replacement of liver tissue by the cancer. However, of the 51 patients, the livers of 37 were examined at laparotomy and of these, 26 had no gross evidence of metastatic involvement. The cancerous infiltration into the livers of the other 11 patients was minimal. There was no higher incidence of low plasma vitamin A levels among the patients with metastases to the liver than among those whose livers were free of cancer.

Nevertheless, the patients with gastro-intestinal cancer presented in this communication did have evidence of hepatic insufficiency. This insufficiency was indicated by the fact that 2 or more of 8 liver functions which were tested in each patient of this group were discovered to be abnormal. The details of this study will form the subject of a subsequent report.

To date, 19 patients have been studied who have had successful resection of gastro-intestinal can- 
cer from 3 months to 10 years ago. Fourteen of these patients had plasma levels of vitamin A within normal limits and considerably less evidence of hepatic dysfunction than did the patients bearing gastro-intestinal cancer.

The hepatic dysfunction found to exist in patients with cancer of the gastro-intestinal tract might account for a derangement in the metabolic processes which involve vitamin $\mathrm{A}$ formation and storage. It is impossible to state definitely, as yet, whether or not the hepatic dysfunction and the low plasma level of vitamin A found in the patients with gastro-intestinal cancer are dependent on the presence of cancer in the organism, but this appears probable from the evidence.

\section{SUMMARY AND CONCLUSIONS}

1. The levels of vitamin $A$ in the plasma of patients with gastro-intestinal cancer were found to be below the normal range in 86 per cent of the patients examined.

2. The probable explanation for the low plasma levels of vitamin $A$ is thought to be (a) an inadequate ingestion and absorption of the vitamin, (b) an hepatic dysfunction as concerns the storage of vitamin $A$ or its formation from carotene.

3. It has been shown that in a proportion of the patients studied, a dietary deficiency or malabsorption of the vitamin could not explain the low plasma vitamin A values.

4. Patients who have had successful resection of gastro-intestinal cancer have a much lower incidence of reduced plasma levels of vitamin A than do the patients in whom gastro-intestinal cancer is still present.

5. The administration of yeast and lipocaic, themselves free of carotenoids, raised the reduced plasma levels of vitamin $A$ in patients with gastro-intestinal cancer. This property of the yeast and lipocaic could have been due to choline chloride and perhaps to other lipotropic substances contained in these materials.

6. A high incidence of reduced vitamin A levels also was found in the plasma of patients with other malignant diseases; namely, with lymphomas, cancer of the head of the pancreas, and bone sarcoma.

\section{BIBLIOGRAPHY}

1. Collins, S. D., Gover, M., and Dorn, H. F., Trend and geographic variation in cancer mortality and prevalence, with special reference to gastric cancer. J. of Natl. Cancer Inst., 1941, 1, 425.

2. Rhoads, C. P., Gastric cancer as a sequel to gastritis, particularly the gastritis of pernicious anemia. J. of Natl. Cancer Inst., 1941, 1, 511.

3. Klein, A. J., and Palmer, W. L., Experimental gastric carcinoma: A critical review with comments on the criteria of induced malignancy. J. of Natl. Cancer Inst., 1941, 1, 559.

4. Dann, W. J., and Evelyn, K. A., The determination of vitamin $A$ with the photoelectric colorimeter. Biochem. J., 1938, 32, 1008.

5. Clausen, S. W., and McCoord, A. B., The carotenoids and vitamin $A$ of the blood. J. Pediat., 1938, 13, 635.

6. Kimble, M. S., The photocolorimetric determination of vitamin $A$ and carotene in human plasma. J. Lab. and Clin. Med., 1939, 24, 1055.

7. Koehn, C. J., and Sherman, W. C., The determination of vitamin $A$ and carotene with the photoelectric colorimeter. J. Biol. Chem., 1940, 132, 527.

8. Atkin, L., Schultz, A. S., and Frey, C. N., Ultramicrodetermination of thiamine by the fermentation method. J. Biol. Chem., 1939, 129, 471.

9. Ferrebee, J. W., Urinary excretion of riboflavin. Fluorometric methods for its estimation. J. Clin. Invest., 1940, 19, 251.

10. Bessey, O. A., and Wolbach, S. B., The Vitamins. Am. Med. Assoc., Chicago, 1939, p. 34, 35.

11. Axelrod, A. E., Spies, T. D., and Elvehjem, C. A., A study of urinary riboflavin excretion in man. J. Clin. Invest., 1941, 20, 229.

12. Steininger, G., Roberts, L. J., and Brenner, S., Vita$\min A$ in the blood of normal adults; the effect of depletion diet on the blood values and biophotometric readings. J. A. M. A., 1939, 113, 2381.

13. Murrill, W. A., and others, Vitamin $A$ and carotene. II. Vitamin A and carotene metabolism in diabetics and normals. J. Clin. Invest., 1941, 20, 395.

14. Dragstedt, L. R., Lipocaic, the new pancreas hormone. Northwest Med., 1938, 37, 33.

15. Best, C. H., Ferguson, G. C., and Hershey, J. M., Choline and liver fat in the diabetic dog. $J$. Physiol., 1933, 79, 94.

16. Kaplan, A., and Chaikoff, I. L., The effect of choline on lipid metabolism of blood and liver in the completely depancreatized dog maintained with insulin. J. Biol. Chem., 1937, 120, 647.

17. Corbet, R. E., Geisinger, H. H., and Holmes, H. N., Substances which interfere with the antimony trichloride test for vitamin A. J. Biol. Chem., 1933, 100, 657.

18. Munsell, H. E., The Vitamins. Am. Med. Assoc., Chicago, 1939, 97. 
19. Barthen, C. L., and Leonard, C. S., A comparison of spectrophotometric and biological assays for vitamin A. J. Am. Pharm. A., 1937, 26, 515.

20. Baxter, J. G., and Robeson, C. D., Crystalline vitamin A palmitate and vitamin A alcohol. Science, 1940, 92, 203.

21. Mead, T. H., Underhill, S. W. F., and Conward, K. H., Crystalline esters of vitamin A. I. Preparation and properties. Biochem. J., 1939, 33, 589.

22. Embree, N. D., Occurrence of cyclized vitamin A in fish liver oils. J. Biol. Chem., 1939, 128, 187.

23. Best, C. H., Personal communication.

24. Dragstedt, L. R., Van Prohaska, J., and Harms, H. $P$., Observations on a substance in pancreas (a fat metabolizing hormone) which permits survival and prevents changes in depancreatized dogs. Am. J. Physiol., 1936, 117, 175.

25. Van Prohaska, J., Dragstedt, L. R., and Harms, $H$. $P$., The relation of pancreatic juice to fatty infiltration and degeneration of the liver in the depancreatized dog. Am. J. Physiol., 1936, 117, 166.

26. McHenry, E. W., and Gavin, G., The effects of liver and pancreas extracts upon fat synthesis and metabolism. J. Biol. Chem., 1940, 134, 683.

27. Best, C. H., and Channon, H. J., The action of choline and other substances in the prevention and cure of fatty livers. Biochem. J., 1935, 29, 2651.

28. Best, C. H., and Ridout, J. H., Choline as a dietary factor. Ann. Rev. Biochem., 1939, 8, 349.

29. Newman, M. S., and Anderson, R. J., The chemistry of the lipids of yeast. I. The composition of the phospholipids. J. Biol. Chem., 1933, 102, 229.

30. Best, C. H., and Ridout, J. H., The pancreas and the deposition of fat in the liver. Am. J. Physiol., 1938, 122, 67.

31. Harris, L. J., and Abbasy, M. A., The dark adaptation test: its reliability as a test for vitamin A deficiency. Lancet, 1939, 2, 1299 and 1355.

32. Thomson, A. M., and others, A study of diet in relation to health: dark adaptation as an index of adequate vitamin $A$ intake. III. The relation of diet to rate and extent of dark adaptation. Brit. J. Ophthal., 1939, 23, 697.

33. Patton, E. W., Sutton, W. R., and Youmans, J. B., The relation of dark adaptation (determined by the Hecht adaptometer) to blood carotene and blood vitamin A levels. J. Clin. Invest. (Proc.), 1941, 20, 463.
34. Moore, T., Vitamin A and carotene. VII. The distribution of vitamin $A$ and carotene in the body of the rat. Biochem. J., 1931, 25, 275.

35. Sherman, H. C., and Boynton, L. C., Quantitative experiments upon the occurrence and distribution of vitamin A in the body. J. Am. Chem. Soc., $1925,47,1646$.

36. Miller, L. L., and Whipple, G. H., Chloroform liver injury increases as protein stores decrease. Studies in nitrogen metabolism in these dogs. Am. J. M. Sc., 1940, 199, 204.

37. Madden, S. C., and Whipple, G. H., Plasma proteins: their source, production and utilization. Physiol. Reviews, 1940, 20, 194.

38. Wintrobe, M. M., and Schumaker, H. S., Jr., The occurrence of macrocytic anemia in association with disorder of the liver together with a consideration of the relation of this anemia to pernicious anemia.. Bull. Johns Hopkins Hosp., 1933, 52, 387.

39. Popper, H., Histologic demonstration of vitamin A in the human liver by means of fluorescence microscopy. Proc. Soc. Exper. Biol. and Med., 1940, 43, 234.

40. Popper, H., Vitamin A: the distribution of vitamin A in the body. J. Mt. Sinai Hosp., 1940, 7, 119.

41. Popper, H., and Greenburg, R., The distribution of vitamin $A$ in the rat as studied by fluorescence microscopy. Am. J. Physiol. (Proc.), 1940, 129, 442.

42. Wohl, M. G., and Feldman, J. B., Vitamin A deficiency in diseases of the liver: its detection by dark-adaptation method. J. Lab. and Clin. Med., $1940,25,485$.

43. With, T. K., Investigations on transformation of carotene to vitamin $A$ in the liver of rats with special reference to rate of the process. Nord. Med. (Hospitalstid), 1939, 3, 2901.

44. Olcott, D. C., and McCann, D. C., Carotenase. The transformation of carotene to vitamin $A$ in vitro. J. Biol. Chem., 1931, 94, 185.

45. Greaves, J. D., and Schmidt, C. L. A., The utilization of carotene by jaundiced and phosphorus treated vitamin A deficient rats. Am. J. Physiol., 1935, 111, 502.

46. Bessey, O. A., and Wolbach, S. B., The Vitamins. Am. Med. Assoc., Chicago, 1939, p. 36. 